\title{
A study on management of maternal anemia with infusion of intravenous iron sucrose and its outcome in management of anemia
}

\author{
Uma Maheswari R.*, R. Veerakumaran
}

Department of Obstetrics and Gynecology, Vanavil Medical Centre, Chennai, Tamil Nadu, India

Received: 03 December 2018

Accepted: 12 December 2018

\section{*Correspondence:}

Dr. Uma Maheswari R.,

E-mail: drumamaheswari@yahoo.co.in

Copyright: () the author(s), publisher and licensee Medip Academy. This is an open-access article distributed under the terms of the Creative Commons Attribution Non-Commercial License, which permits unrestricted non-commercial use, distribution, and reproduction in any medium, provided the original work is properly cited.

\begin{abstract}
Background: In India, women become pregnant with low baseline hemoglobin level resulting in high incidence of moderate to severe anemia in pregnancy where oral iron therapy cannot meet the requirement. Pregnant women with moderate anemia are to be treated with parenteral iron therapy. The aim of the study is to the infusion of intravenous iron sucrose and its outcome in the management of anemia.

Methods: Totally 100 pregnant females were included in the study. The study period was from January 2018-July 2018 at vanavil medical center in Chennai. 50 Patients of Group A was given oral iron tablets containing 100mg of elemental iron. 50 patients of Group B was given a total of $1000 \mathrm{mg}$ of intravenous iron sucrose divided into five doses of $200 \mathrm{mg}$ each at weekly intervals. Estimation of hemoglobin was started 4 weeks after commencement of iron therapy and then repeated every 4 weeks till 36 weeks of gestation, pre-delivery and postpartum.

Results: Target hemoglobin levels were achieved in 4 weeks' time in 19 (76\%) patients in the iron sucrose group as compared to $08(32 \%)$ of patients in the oral iron group. There was a significant improvement in the various hematological parameters in iv sucrose group as compared to patients in the oral iron group. There were no significant allergic reactions in iv sucrose group.

Conclusions: Our results showed that intravenous iron sucrose therapy was effective to treat moderate anemia in pregnant women. Intramuscular preparations are known to be associated with local side-effects. Iron sucrose complex iv therapy was with negligible side effects. It caused a rapid rise in hemoglobin level and the replacement of stores was faster. Long term comparative studies are required to assess if they can be used at a peripheral level.
\end{abstract}

Keywords: Anaemia, Intravenous sucrose, Parenteral iron therapy, Pregnant women

\section{INTRODUCTION}

As one of the important factors influencing maternal morbidity and mortality and also the health of the newborn, Anemia has defied over 3 decades of public health intervention and continues to affect a majority of pregnant women in the state. Anemia in pregnancy is associated with high maternal morbidity and mortality. ${ }^{1}$ Prevalence was high in all States of the country with considerable variations in moderate to severe anemia. Other factors responsible for high incidence of anemia in our country include early marriage, teenage pregnancy, multiple pregnancies, less birth spacing, phytate-rich Indian diet, low iron, and folic acid intake and high incidence of worm infections in Indian population. ${ }^{2}$ WHO defines anemia as hemoglobin $(\mathrm{Hb})<11 \mathrm{~g} \% \mathrm{In}$ India, the ICMR classification of iron deficiency anemia is: $8-11 \mathrm{~g} \%$ as mild, $5-8 \mathrm{~g} \%$ as moderate and $<5 \mathrm{~g} \%$ as severe anemia. ${ }^{1}$ In absence of interfering factors, serum ferritin $<12-15 \mu \mathrm{g} / 1$ is considered as iron deficiency. ${ }^{3}$ The first choice for prophylaxis and treatment of mild iron deficiency anemia in pregnancy is oral iron therapy. But 
in patients with moderate and severe anemia, oral therapy takes a long time and compliance is a big issue in our country. ${ }^{4}$

Thus, pregnant women with moderate anemia should be better treated with parenteral iron therapy and/or blood transfusion depending upon individual basis (degree of anemia, hemodynamic status, period of gestation, etc.).Various parenteral iron preparations are available in the market which can be given either intravenously or intramuscularly. ${ }^{5}$

Initially, iron dextran and iron sorbitol citrate were started. But test dose was required to be given before these injections as severe anaphylactic reactions were reported with intravenous iron dextran. Iron sucrose has been reported to be safe and effective during pregnancy. The injection can be given without test dose. ${ }^{6}$ As one of the important factors influencing maternal morbidity and mortality and also the health of the newborn, anemia has defied over three decades of public health intervention and continues to affect a majority of pregnant women in the state. Anemia in pregnancy is associated with high maternal morbidity and mortality. ${ }^{7}$

Maternal anemia is associated with poor intra-uterine growth and conceiving of low-birth-weight babies. This, in turn, could result in higher perinatal morbidity, infant mortality, developmental delays, reduction of placental weight, volume and surface area. ${ }^{8}$ There is a striking difference in the mean birth weight of the infants born of anemic and non-anemic mothers. This has resulted in 12 to 28 percent of the fetal loss, 30 percent of perinatal deaths and 7 to 10 percent of neonatal deaths. ${ }^{9}$

Anemia during the second trimester is associated with preterm birth. Preterm delivery is increased fivefold for iron deficiency anemia and doubled for other anemia. Fifteen to twenty percent of maternal deaths are directly or indirectly due to anemia and the mortality is higher if postpartum hemorrhage occurs in anemic mothers. ${ }^{10}$

\section{METHODS}

Totally 100 pregnant females were included in the study. The study period was from January 2018-July 2018 at Vanavil Medical Center in Chennai. 50 Patients OF Group A was given oral iron tablets containing100mg of elemental iron. 50 patients of Group B were given a total of $1000 \mathrm{mg}$ of intravenous iron sucrose divided into five doses of $200 \mathrm{mg}$ each at weekly intervals. Estimation of hemoglobin was started 4 weeks after commencement of iron therapy and then repeated every 4 weeks till 36 weeks of gestation, pre-delivery and postpartum.

\section{Inclusion criteria}

- Women who are $>24$ weeks of gestation with $\mathrm{Hb} \leq 7 \mathrm{gm} / \mathrm{dl}$, who agree to participate in this study in writing.

\section{Exclusion criteria}

- From the study we excluded cases with a diagnosis of placenta previa,

- Placenta abruption, pre-eclampsia and clotting disorders

- Patients who have participated in another clinical study in recent 3 months, or shown intolerance or hypersensitivity to iron therapy

- Hemolytic anemia,

- Hemoglobinopathies (thalassemia, sickle cell), bleeding tendency,

- Hypersplenism

- Chronic heart failure, Class II-IV heart disease, uncontrolled arterial hypertension (DBP $\geq$ $115 \mathrm{mmHg}$ ), deep vein thrombosis, thrombocytosis.

- Intolerance to oral iron

- Poor compliance to oral iron

- Inadequate absorption due to gastrointestinal disorders-malabsorption a chlorhydria

- Lack of response to oral iron

- Pregnant women with severe IDA, presenting late in pregnancy

- Post-partum anemia.

\section{Dosage calculation}

Administration of IV Iron sucrose is based on the total Iron deficit.

Total dose in $\mathrm{mg}=$ Body Wt. $\mathrm{X}$ (Target $\mathrm{Hb}-$ Actual $\mathrm{Hb}$ ) X 2.4

This is followed by $10 \mathrm{mg} / \mathrm{kg}$ body weight to replenish the Iron stores.

Dose is based on the following method:2The body weight here is pre-pregnancy body weight, the target $\mathrm{Hb}$ is measured in $\mathrm{gm} /$ liter, and 0.24 is a correction factor that takes into account the patient's blood volume, estimated at $7 \%$ of body weight and Haemoglobin iron content; Since we are measuring $\mathrm{Hb}$ in $\mathrm{g} / \mathrm{dl}$ or $\mathrm{gm} \%$ in routine measurements, the correction factor is adjusted to $0.24 \mathrm{X}$ $10=2.4$.

\section{Iron sucrose is administered by intravenous Infusion}

The infusion is administered as every $2.5 \mathrm{ml}$ Iron Sucrose diluted exclusively in a maximum of $100 \mathrm{ml}$ of $0.9 \%$ $\mathrm{NaCl}$, immediately prior to infusion. The rate should be of $100 \mathrm{ml} / 30$ minutes. Example: To give $100 \mathrm{mg}$ of elemental iron, two ampoules of $2.5 \mathrm{ml}$ or one ampoule of $5 \mathrm{ml}$ should be diluted in $100 \mathrm{ml} \mathrm{NS}$ and this should be infused over the period of 30 minutes. The unused diluted solution must be discarded. Maximum dose: A maximum of $200 \mathrm{mg}$ of elemental iron can be given in one dose (in $100 \mathrm{ml} \mathrm{NS}$ ). This should be infused over 30 minutes, can be given 1-3 times per week or on alternate days. A total 
dose of $1.0 \mathrm{gm}$ can be given in 4-10 sittings (over a period of 1 month).

\section{Side effects of Iron sucrose}

There can be hypotension, headache, vomiting, nausea, dizziness, joint ache, paresthesia, abdominal \& muscle pain, edema, and cardiovascular collapse Side effects are rare in a dose of $100 \mathrm{mg} /$ day. They appear if it is infused in higher dose or the rate of infusion is very slow and very fast (the norm of $100 \mathrm{ml} / 30$ minutes should be followed).

The primary outcome measures were hemoglobin and serum ferritin levels after 4 and 8 wks. Secondary outcome measures were an improvement in serum iron levels, reticulocyte count, any adverse effects and perinatal outcome [period of gestation (POG) at the time of delivery, type of birth, postpartum hemorrhage, need of blood transfusion and fetal birth weight].

\section{Statistical analysis}

Data were analyzed using SPSS software version 22 and MedCalc software version 15. Data were interpreted using descriptive and inferential statistics. The Chisquare test was used to test the statistical significance of the relationship between two variables.

\section{RESULTS}

Table 1 shows while a comparable increase in hemoglobin was observed for both administration routes (mean increase $1.15 \mathrm{gm} / \mathrm{dL}$ in the intravenous group vs $0.88 \mathrm{~g} / \mathrm{dL}$ in the oral group in the first week of treatment. Both groups showed an immediate reticulocyte response and continuous increase in hematocrit i.v. iron sucrose had greater increases in hematocrit $(\%)$ from the first week of treatment $22.2 \pm 1.74$ as compared to $20.4 \pm 2.49$ in oral iron, which is, statistically significant $(\mathrm{P}<0.0006)$.

Table 1: Basic demographic profile of pregnant mothers $(n=100)$.

\begin{tabular}{|l|l|l|l|}
\hline Parameters & IV Sucrose & Oral Iron & P-value \\
\hline Mean Age (Years) & $28.1 \pm 5.36$ & $27.8 \pm 5.28$ & 0.838 \\
\hline Mean Weight $(\mathrm{Kg})$ & $54.5 \pm 3.45$ & $55.9 \pm 2.07$ & 0.108 \\
\hline Parity (Primi/ Multi) & $10 / 15(40 \% / 60 \%)$ & $08 / 17(32 \% / 68 \%)$ & 0.556 \\
\hline Mean gestational age (weeks) & $28.2 \pm 2.30$ & $28.87 \pm 2.40$ & 0.165 \\
\hline Mean Haemoglobin $(\mathrm{gm} / \mathrm{dl})$ & $6.27 \pm 0.48$ & $5.95 \pm 0.62$ & 0.087 \\
\hline Mean PCV $(\%)$ & $18.8 \pm 1.46$ & $17.8 \pm 1.86$ & 0.087 \\
\hline Mean Ferritin $(\mu \mathrm{g} / \mathrm{l})$ & $9.44 \pm 3.01$ & $10 \pm 1.9$ & 0.375 \\
\hline
\end{tabular}

Table 2: Hematological indices between two groups.

\begin{tabular}{|c|c|c|c|c|}
\hline Hematological indices & Levels & IV Sucrose & Oral Iron & P-value \\
\hline \multirow{2}{*}{$\mathrm{Hb}(\mathrm{gm} / \mathrm{dl})$} & Baseline & $6.27 \pm 0.48$ & $5.94 \pm 0.62$ & 0.087 \\
\hline & Four weeks & $11.3 \pm 0.70$ & $17.8 \pm 1.76$ & $0.0006 *$ \\
\hline \multirow{2}{*}{ Hematocrit (\%) } & Baseline & $18.8 \pm 1.46$ & $30.77 \pm 3.23$ & 0.087 \\
\hline & Four weeks & $33.9 \pm 2.11$ & $10.0 \pm 1.90$ & $0.0006 *$ \\
\hline Ferritin $(\mu \mathrm{g} / \mathrm{l})$ & Baseline & $9.44 \pm 3.01$ & $160.8 \pm 33.1$ & 0.375 \\
\hline \multirow{2}{*}{ Transferrin Saturation (\%) } & Four weeks & $295.5 \pm 45.1$ & $8.08 \pm 1.15$ & $<0.0001 *$ \\
\hline & Baseline & $7.24 \pm 1.73$ & $22.2 \pm 1.56$ & 0.070 \\
\hline \multirow{2}{*}{ Reticlocyte Count (\%) } & Baseline & $1.69 \pm 0.14$ & $4.2 \pm 0.19$ & 0.292 \\
\hline & Four weeks & $4.27 \pm 0.18$ & $25.6 \pm 2.06$ & 0.209 \\
\hline $\mathrm{MCHC}(\mathrm{gm} \%)$ & Baseline & $26.0 \pm 1.73$ & $32.08 \pm 1.41$ & 0.574 \\
\hline \multirow{2}{*}{$\operatorname{MCV}(\mathrm{fl})$} & Four weeks & $33.1 \pm 0.97$ & $70.1 \pm 2.93$ & $0.009 *$ \\
\hline & Baseline & $71.28 \pm 0.97$ & $85.8 \pm 3.97$ & 0.108 \\
\hline \multirow{2}{*}{ Hypochromasia (\%) } & Four weeks & $93 \pm 1.13$ & $45.6 \pm 1.35$ & $<0.0001 *$ \\
\hline & Baseline & $46 \pm 3.82$ & $3.01 \pm 0.95$ & $0.001 *$ \\
\hline
\end{tabular}

*: statistically significant difference in the study

Table 2 shows target hemoglobin level of $11.0 \mathrm{~g} / \mathrm{dl}$ was reached in 4, weeks' time in i.v. iron sucrose. None of the patients in oral iron had a target hemoglobin level of $11.0 \mathrm{~g} / \mathrm{dl}$ in 4 weeks' time with a mean hemoglobin value of $9.73 \pm 1.23 \mathrm{~g} / \mathrm{dL}$ at the end of 4 weeks, which is statistically significant $(\mathrm{P}<0.00002)$. Ferritin level $(\mu \mathrm{g} / 1)$, transferrin saturation(\%), MCHC (gm\%), $\mathrm{MCV}(\mathrm{fl})$, Hypochromasia $(\%)$ on peripheral smear increased continuously until the end of these therapy in both groups and was higher in i.v. iron sucrose which, is statistically 
significant. Nineteen $(76 \%)$ women in i.v. iron sucrose had normal antepartum hemoglobin levels $(>11.0 \mathrm{~g} / \mathrm{dL})$ as compared to $8(32 \%)$ women in oral iron, which is statistically significant $(\mathrm{P}<0.002)$

\section{DISCUSSION}

Anemia is a common medical disorder that contributes significantly to maternal morbidity and mortality, intrauterine growth retardation, pre-term delivery, and perinatal morbidity and mortality. ${ }^{11}$ In India $>90 \%$ of anemia cases are estimated to be due to iron deficiency because high iron requirements during pregnancy are not easily fulfilled by dietary intake, especially when iron bio-availability is poor because of religious reasons, poverty, or both, the Indian population observes dietary patterns that are largely vegetarian.

Diet alone cannot supply the $30-40 \mathrm{mg}$ iron that is required for absorption of the 4-6 $\mathrm{mg}$ iron/day needed during the latter stage of pregnancy. ${ }^{12}$ Iron supplementation is strongly recommended for all pregnant women in developing countries.

Oral iron intake has been the treatment of choice for the same. The patient's response is fast, with a significant increase in reticulocyte count within 5-10 days and hemoglobin rises by $0.3-1.0 \mathrm{~g}$ per week. ${ }^{13}$ However, it has been recognized for decades that oral iron therapy is not adequate for pregnant women with iron deficiency anemia, mainly because of the augmented demand for iron during pregnancy.

Even patients who respond well to oral iron therapy require a long time (months) to reach target hemoglobin. This means that they have to suffer from the iron deficiency for extended periods unnecessarily. ${ }^{14}$

A pregnant woman without anemia may require at least $1000 \mathrm{mg}$ of elemental iron to be delivered to the hemopoietic organs while an anemic one may need more than 2600 mg. ${ }^{15}$ This requirement cannot be met by oral route in the majority of patients because of limited absorption, bioavailability, and compliance. In addition, oral iron therapy is further complicated by the adverse effects of pregnancy on the gastrointestinal tract Thus, parenteral iron supplementation has quite rightly grown in popularity over the past few decades. ${ }^{16}$

Parenteral administration by intramuscular injection is a painful alternative with a variable degree of efficacy. Parenteral exposure to iron dextran imposed a series of serious risks to the health of the recipient. ${ }^{17}$ Among a sample of only 100 women in the intramuscular iron group, the documented frequency of local pain, skin staining, fever, and systemic symptoms- not to mention adverse reactions requiring hospitalization was unacceptable. $^{18}$ Many studies have stressed that intramuscular therapy should be discouraged because of its adverse effects which include pain, irregular absorption, staining, and malignancy. Intramuscular iron sucrose complex is particularly contraindicated because of poor absorption. ${ }^{19}$

They also stated that when iron dextran is given intravenously up to $30 \%$ of patients suffer from adverse effects which include arthritis, fever, urticaria, and anaphylaxis. In practice, physicians are often faced with poor compliance, justified by digestive side effects that can lead to worsening anemia. In these cases, the parenteral forms of administration are indicated, as well as those in which the oral treatment is ineffective. ${ }^{20}$

Even patients who respond well to oral iron therapy require a long time (months) to reach target $\mathrm{Hb}$ compared with weeks required in case of treatment with parenteral iron. The use of intramuscular iron preparations is discouraged because of pain, irregular absorption, and staining. ${ }^{21}$ Blood transfusion may improve symptomatic anemia quickly but there is a risk of a transfusion reaction and blood born infection transmission This indicates that as the severity of anemia increase the response to iron sucrose therapy becomes excellent. Because as soon as tissues iron deficiency is established, the serum Transferrin concentration increases in direct proportion to the degree of iron deficiency. ${ }^{22}$ Like most of the other studies, there were no major adverse reactions noted in any patient in present study. The present study shows that of i.v. iron sucrose significantly $(\mathrm{P}<0.00002)$ increase hemoglobin levels within 4 weeks. There were no major adverse reactions. $^{23}$

\section{CONCLUSION}

Intravenous iron therapy is safe, convenient and more effective than oral iron therapy in the treatment of iron deficiency anemia during pregnancy. Limitations with intravenous iron replacement include the need for medical supervision in the setting of limited healthcare resources; the need for patients to take multiple days off work and the cost of IV iron.

\section{ACKNOWLEDGMENTS}

Authors would like to thank Department of Obstetrics and Gynecology, Vanavil Medical Centre, Marimalai Nagar, Chennai for helping with data collection and laboratory analyses for completing research work.

Funding: No funding sources

Conflict of interest: None declared

Ethical approval: The study was approved by the Institutional Ethics Committee

\section{REFERENCES}

1. Kriplani A, Mahey R, Dash BB, Kulshreshta V, Agarwal N, Bhatla N. Intravenous iron sucrose therapy for moderate to severe anemia in pregnancy. Indian J Med Res. 2013;138(1):78-82. 
2. Al-Momen AK, Al-Meshari A, Al-Nuaim L, Saddique A, Abotalib Z, Khashogji T. Intravenous iron sucrose complex in treatment of iron deficiency anemia during pregnancy. Euro J Obstet Gynaecol Reprod Biol.2006;69(2):121-4.

3. Auerbach M, Witt D, Toler W, Fierstein M, Lerner RG, Ballard H. Clinical use of the total dose intravenous infusion of iron dextran. J Lab Clinic Med. 1988;111(5):560-5.

4. Bailie GR, Clark JA, Lane CE, Lane PL. Hypersensitivity reactions and deaths associated with intravenous iron preparations. Nephrol Dial Transplant. 2005;20(7):1443-9.

5. Bashiri A, Burstein E, Sheiner E, Mazor M. Anaemia during Pregnancy and treatment with intravenous iron: review of the literature. Eur J Obstet Gynecol Reprod Biol. 2003;110(1):2-7.

6. Bayoumeu F, Subiran-Buisset C, Baka NE, Legagneur H, Monnier-Barbarino P, Laxenaire MC. Iron therapy in iron deficiency anemia in pregnancy: intravenous route versus oral route. Europ J Obstet Gynecol Reprod Biol. 2005;123:S15-9.

7. Bayoumeu F, Subiran-Buisset C, Baka NE, Legagneur H, Monnier-Barbarino P, Laxenaire MC. Iron therapy in iron deficiency anemia in pregnancy: Intravenous route versus oral route. Am J Obstet Gynecol. 2002;186 (3):518-22.

8. Bencaiova G. Iron prophylaxis in pregnancy. Intravenous iron verses oral route. Eur J Obstet Gynecol Reprod Biol. 2009;144(2):135-9.

9. Bhandari N, Russel R. Intravenous versus oral iron therapy in postpartum anemia. BJOC. 2006; 113(11):1248-52.

10. Breyman C. The use of iron sucrose complex for anemia in pregnancy and postpartum period. Semen Hematology. 2006;43:S28-31.

11. Bhatt RV, Joshi SK, Shah MC, Total dose intravenous infusion of iron-dextran (imferon) in severe anemia. Am J Obstet Gynecol 2006. 94(8):1098-102.

12. Litton E, JXiao J, Ho KM. Safety and efficacy of intravenous iron therapy in reducing the requirement of allogenic blood transfusions. Systematic review and meta-analysis of RCT. BMJ. 2013;347:4822.

13. Ezzati M, Lopus AD, Dodgers A, Vander HS, Murray C. Selected major risk factors and global and regional burden of disease. Lancet. 2002;360(9343):1347-60.
14. Christoph P, Schuller C, Studer H, Irion O, De Tejada BM, Surbek D. IV iron treatment in pregnancy; comparison of high dose ferric carboxy maltose Vs iron sucrose. J Perinat Med. 2012;40(5):469-74.

15. Hallak M, Sharon A, Duckman R, Auslender R, Abramovici. Supplementing iron intravenously in pregnancy. A way to avoid blood transfusions. J Reprod Med. 1997;42(11):99-103

16. KalaivaniK, Prevalence and consequences of anemia in pregnancy. Indian J Med. Res. 2009:130(5);62733.

17. Krafft A, Perewusnyk G, Hänseler E, Quack K, Huch R, Breymann C. Effect of postpartum iron supplementation on red cell and iron parameters in nonanaemic iron-deficient women: a randomized placebo-controlled study. BJOG. 2005;112(4):44550.

18. Mahomed K. Iron and folate supplementation in pregnancy. In the Cochrane library; Oxford update. 2002:90(2):167-9

19. Milman N, Bergholt T, Byg K, Erikson L, Graudal $\mathrm{N}$. Iron status and iron balance during pregnancy, a critical reappraisal of iron supplementation. Acta Obstet Gynecol Scand. 1999;78(9):749-57.

20. Momen AK, Meshari A, Nuaim L, Saddique A, Abotalib Z, Khashogji $\mathrm{T}$, et al. Intravenous iron sucrose in the treatment of iron deficiency anemia during pregnancy. Reprod boil.1996;69(2):121-4.

21. Perewusnyk G., Huch R., Huch A., Breymann C. Parenteral iron therapy in obstetrics: 8 years' experience with the iron-sucrose complex. $\mathrm{Br} \mathrm{J}$ Nutr.2009;88(1):3-10.

22. Rohilla M, Raveendran A, Dhaliwal LK, Chopra S. Severe anemia in pregnancy: a tertiary hospital experience from northern India. J. Obstet Gynecol. 2010;30(7):694-6.

23. Robinson C., Bell DN, Sturdy JH, A Possible association of malignant neoplasm with iron dextran injection. Br Med J. 2010;2(5199):648-50.

Cite this article as: Maheswari UR, Veerakumaran R. A study on management of maternal anemia with infusion of intravenous iron sucrose and its outcome in management of anemia. Int $\mathbf{J}$ Reprod Contracept Obstet Gynecol 2019;8:39-43. 